\title{
Rectangular Ring Antenna Excited by Circular Disc Monopole for WiMAX System
}

\author{
Souphanna Vongsack, ${ }^{1}$ Chuwong Phongcharoenpanich,, ${ }^{1}$ Sompol Kosulvit, ${ }^{1}$ \\ Kazuhiko Hamamoto, ${ }^{2}$ and Toshio Wakabayashi ${ }^{3}$ \\ ${ }^{1}$ Faculty of Engineering, King Mongkut's Institute of Technology Ladkrabang, Bangkok 10520, Thailand \\ ${ }^{2}$ School of Information and Telecommunication Engineering, Tokai University, Kanagawa 259-1292, Japan \\ ${ }^{3}$ Malaysia-Japan International Institute of Technology (MJITT), Universiti Teknologi Malaysia, Kuala Lumpur 54100, Malaysia \\ Correspondence should be addressed to Chuwong Phongcharoenpanich; pchuwong@gmail.com
}

Received 13 July 2014; Accepted 29 October 2014; Published 13 November 2014

Academic Editor: Giampiero Lovat

Copyright (C) 2014 Souphanna Vongsack et al. This is an open access article distributed under the Creative Commons Attribution License, which permits unrestricted use, distribution, and reproduction in any medium, provided the original work is properly cited.

This research presents a rectangular ring antenna excited by a circular disc monopole (CDM) mounted in front of a square reflector. The proposed antenna is designed to cover a frequency range of $2.300-5.825 \mathrm{GHz}$ and thereby is suitable for WiMAX applications. Multiple parametric studies were carried out using the CST Microwave Studio simulation program. A prototype antenna was fabricated and experimented. The measurements were taken and compared with the simulation results, which indicates good agreement between both results. The prototype antenna produces an impedance bandwidth $\left(\left|S_{11}\right|<-10 \mathrm{~dB}\right)$ that covers the WiMAX frequency range and a constant unidirectional radiation pattern $\left(\theta=0^{\circ}\right.$ and $\left.\emptyset=90^{\circ}\right)$. The minimum and maximum gains are 3.7 and $8.7 \mathrm{dBi}$, respectively. The proposed antenna is of compact size and has good unidirectional radiation performance. Thus, it is very suitable for a multitude of WiMAX applications.

\section{Introduction}

Besides an integral part of wireless communications, a wideband antenna is a crucial technology in the short-range, highspeed, and indoor wireless communications. According to [1-4], the WiMAX frequency bands are classified into three frequency bands of $2.500-2.690 \mathrm{GHz}, 3.400-3.690 \mathrm{GHz}$, and $5.250-5.850 \mathrm{GHz}(2.5 / 3.5 / 5.5 \mathrm{GHz})$. Over the past decades, a greater number of countries have utilized cellular base stations for installation of WiMAX antennas. Moreover, advances in mobile communications technology and rapid urbanization help promote the growth of indoor base stations, for example, in buildings, underground train systems, and tunnels. One distinct characteristic of indoor base stations is their omnidirectional radiation pattern, which is however their main drawback since an omnidirectional antenna can cover a limited circular area. This renders the omnidirectional antenna unsuitable for applications in the environment characterized by long and confined spaces in which a unidirectional antenna is more appropriate. In addition, unidirectional antennas are applicable to point-topoint communications. In these environments, for example, streets, highways, tunnels, and corridors, a unidirectional or bidirectional antenna performs better than an omnidirectional antenna [5-11]. To generate a unidirectional beam, a planar reflector $[12,13]$, corner reflector $[14,15]$, parabolic reflector [16], or conical reflector [17] was used with an omnidirectional monopole antenna. The unidirectional bandwidth is narrow and could be enhanced by replacing the linear monopole with a surface monopole, for example, circular, triangular, square, or rectangular monopole [18-22].

To achieve the unidirectional pattern along the WiMAX frequency range of $2.300-5.825 \mathrm{GHz}$, this research proposes a rectangular ring antenna excited by a CDM mounted in 


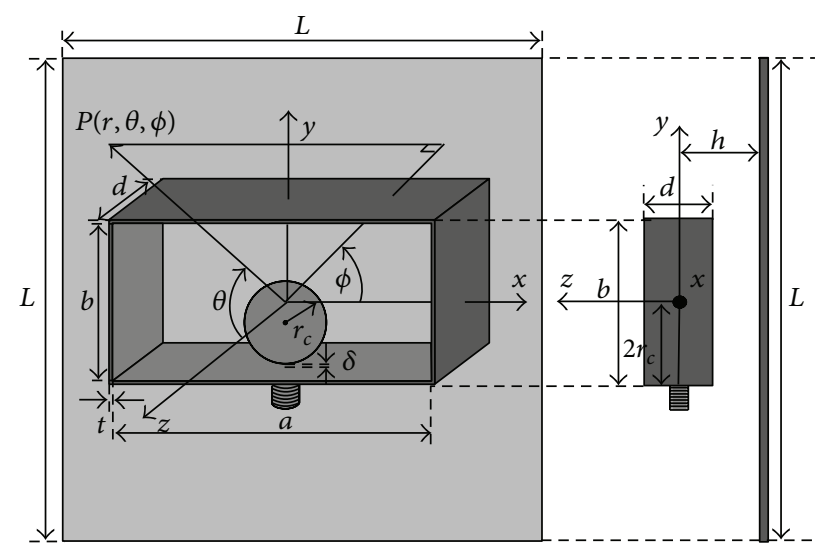

(a) Perspective view

(b) Side view

FIGURE 1: The structure of the proposed antenna with CDM.

front of a square reflector. The simulations and experiments were carried out along the WiMAX frequency band. The proposed antenna's $\left|S_{11}\right|$, radiation pattern, and gain along the WiMAX frequency were simulated using the CST Microwave Studio [23]. Based on the simulation results, the optimal rectangular ring dimensions and CDM radius are $a=$ $7.20 \mathrm{~cm}, b=a / 2, d=2.60 \mathrm{~cm}$, and $r_{c}=1.10 \mathrm{~cm}$, respectively, as $\left|S_{11}\right|<-10 \mathrm{~dB}$ along the WiMAX band. It is however found that the beam direction beyond a higher frequency of $5.5 \mathrm{GHz}$ tilts upward as a result of the asymmetrical areas between the upper and lower portions of the rectangular ring chamber.

The organization of this paper is as follows. Section 1 is the introduction. Section 2 details the structure and parameters of the proposed antenna. Section 3 presents the design principle and the parametric study, while Section 4 compares the simulation and measured results. The concluding remarks are provided in Section 5.

\section{Geometry of the Proposed Antenna}

Figure 1(a) illustrates the structure of the proposed antenna, which consists of a CDM and a rectangular ring with width $a$, height $b$, length $d$, and thickness $t$. The rectangular ring center is at the $y z$-plane origin. The ring is excited by the $\mathrm{CDM}$ on the $y$-axis via a $50 \Omega$ SMA connector to generate vertical polarization. The CDM radius $r_{c}$ and the delta gap $\delta$ are $1.10 \mathrm{~cm}$ and $1.00 \mathrm{~mm}$, respectively. The structure is mounted in front of an $L \times L$ square reflector. The space between the rectangular ring and the reflector is denoted by $h$, as illustrated in Figure 1(b). The antenna radiation pattern is unidirectional with the beam peak pointing in the $z$ direction.

\section{Design Principle and Parametric Study}

The antenna is designed to operate in the WiMAX frequency range of $2.300-5.825 \mathrm{GHz}$. The design principle starts with exciting the rectangular ring with a circular-disc monopole
(CDM), as shown in Figure 1. The initial ring width $a$ of the $2.3 \mathrm{GHz}$ frequency is slightly greater than $\lambda / 2$ (i.e., $6.60 \mathrm{~cm}$ ). The ring height $b$ is proportional to the ring width $a$; that is, $b=a / 2$. The ring length $d$ and thickness $t$ are $3.25 \mathrm{~cm}(\lambda / 4)$ and $2.00 \mathrm{~mm}$, respectively. The rectangular ring is excited by a circular-disc monopole with an $r_{c}$ radius $1.3 \mathrm{~cm}(0.1 \lambda)$. The selected square reflector is $16 \times 16 \mathrm{~cm}(L \times L)$ in dimension with the space $(h)$ between the rectangular ring and the reflector of $3.90 \mathrm{~cm}(0.3 \lambda)$. Both the rectangular ring and the reflector are made of aluminum. Ideally, the width $a$ and height $b$ of a rectangular ring should be minimal to obtain an antenna of a size as compact as possible.

The width $a$ of the proposed rectangular ring follows the following rule, where $\lambda$ (i.e., $13.00 \mathrm{~cm}$ ) is the wavelength at the $2.3 \mathrm{GHz}$ frequency:

$$
0.5 \lambda<a<\lambda .
$$

To enhance the bandwidth, the rectangular ring is thus excited by a circular-disc monopole with an $r_{c}$ radius. The initial circular monopole radius $\left(r_{c}\right)$ is determined by (2) with the predetermined feed gap $(\delta)$ of $1.00 \mathrm{~mm}$ and $0.21 \lambda$ being referenced from [15]:

$$
r_{c}=\frac{(0.21 \lambda-\delta)}{2} .
$$

Parametric studies were carried out to determine the optimal ring dimensions that produce an optimal combination of resonant frequency, radiation pattern, and gain and also are of compact size. Figure 2 illustrates the fractional bandwidths of resonant frequency (closest to the $2.3 \mathrm{GHz}$ frequency) by varying $a$ and $d$ of the rectangular ring antenna which is excited by a CDM. Both the ring antenna and the $\mathrm{CDM}$ are together mounted in front of the square reflector. As shown in Figure 2, the fractional bandwidth of resonant frequencies at $2.3 \mathrm{GHz}$ is achieved with $a$ of $7.20 \mathrm{~cm}(0.553 \lambda)$, $b$ of $3.60 \mathrm{~cm}$, and $d$ of $2.60 \mathrm{~cm}$, which are selected as the design parameters. It is noted that the ring width $a$ of $7.20 \mathrm{~cm}$ $(0.553 \lambda)$ is selected because of the wide bandwidth, compact antenna size, and available material in the market suitable for the mass production.

To determine an optimal matching condition with a wide bandwidth, the space between the CDM and the square reflector $h$ is varied from $1.65(0.21 \lambda)$ to $3.90 \mathrm{~cm}(0.30 \lambda)$. The simulated unidirectional beam is achieved at $h$ of $0.10 \lambda-0.30 \lambda$ and of $0.60 \lambda-0.70 \lambda$, while that with the widest bandwidth is achieved at $h<0.30 \lambda$. The beam splits occur when $h$ is between $0.30 \lambda$ and $0.60 \lambda$. According to [13], the unidirectional beam can also be realized when $h$ is $\geq 0.70 \lambda$. It is found that the radiation pattern becomes split for $h$ between $0.30 \lambda$ and $0.60 \lambda$. The simulation results are shown for $h$ of $1.65-2.90 \mathrm{~cm}$ because while $h$ is $>2.90 \mathrm{~cm}$ the $\left|S_{11}\right|$ cannot cover the frequency bandwidth (e.g., $h=3.15 \mathrm{~cm}$, the $\left|S_{11}\right|>-10 \mathrm{~dB}$ from 4.92 to $\left.5.91 \mathrm{GHz}\right)$. Based on the simulation results (Figure 3), $h$ of $2.40 \mathrm{~cm}(0.184 \lambda)$ is selected as it produces a unidirectional beam with wide bandwidth.

Figures 4(a) and 4(b) show, respectively, the minimum and maximum frequencies $\left(\left|S_{11}\right|<-10 \mathrm{~dB}\right)$ of resonance at $2.3 \mathrm{GHz}$ as a function of $b / a$ by varying $r_{c}$, where $b / a$ is 


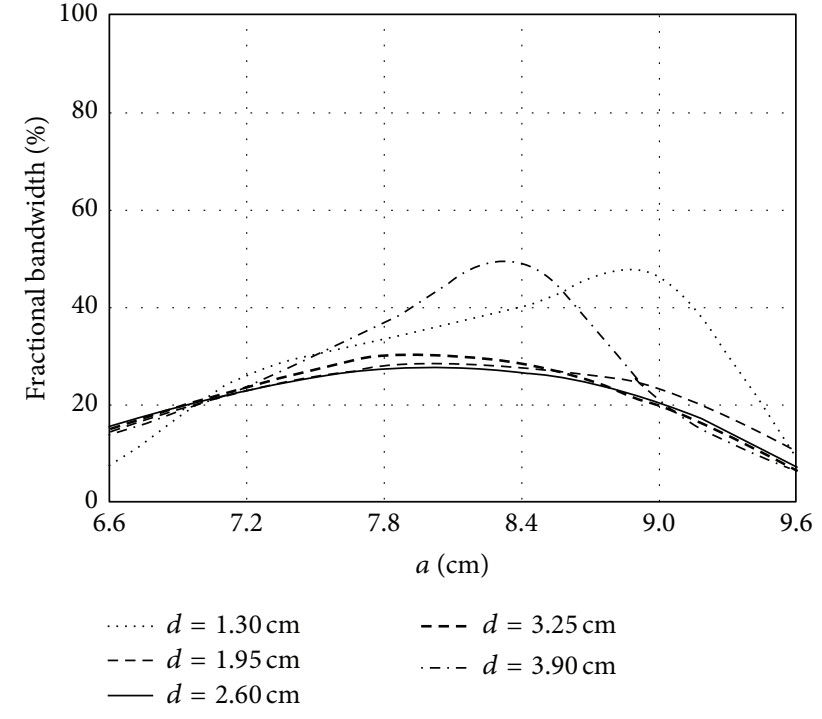

FIGURE 2: Fractional bandwidths of the resonant frequency at $2.3 \mathrm{GHz}$ versus $a$ as a function of $d\left(r_{c}=1.30 \mathrm{~cm}\right.$ and $\left.h=3.90 \mathrm{~cm}\right)$.

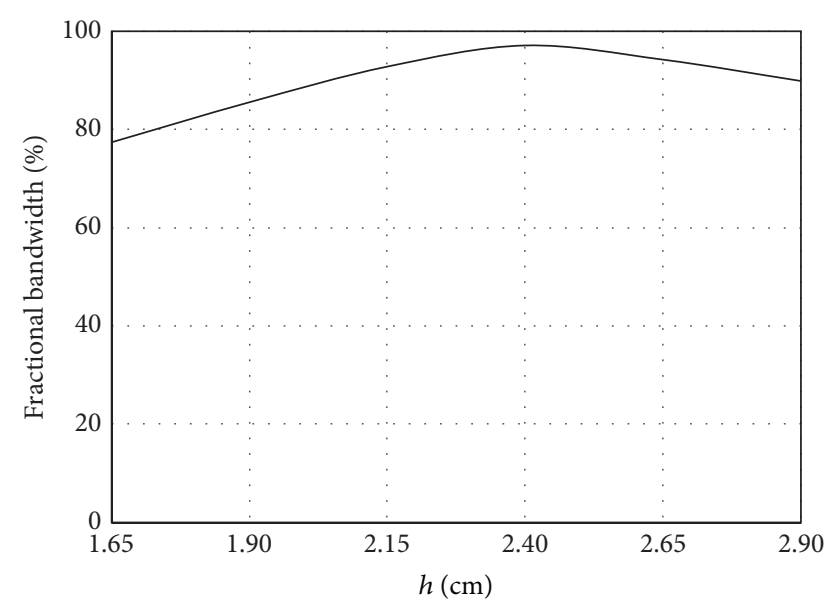

FIGURE 3: Fractional bandwidth of the resonant frequency at $2.3 \mathrm{GHz}$ as a function of $h(a=7.20 \mathrm{~cm}, b=3.60 \mathrm{~cm}, d=2.60 \mathrm{~cm}$, and $\left.r_{c}=1.30 \mathrm{~cm}\right)$.

the ring height. The radius of $\mathrm{CDM}\left(r_{c}\right)$ is varied between 1.00 and $1.40 \mathrm{~cm}$ to determine a ring height $(b / a)$ that gives good resonance at the $2.3 \mathrm{GHz}$ frequency. To produce the rectangular ring of a size as compact as possible, $r_{c}=1.10 \mathrm{~cm}$ for $b=0.48 a$ or $3.40 \mathrm{~cm}$ is selected.

Figure 5 illustrates the impedance bandwidth $\left|S_{11}\right|$ of the resonant frequency closest to $2.3 \mathrm{GHz}$ as a function of $b / a$ of the rectangular ring antenna, assuming a constant $r_{c}$ of $1.10 \mathrm{~cm}$. To achieve the goal of a compact ring antenna with the widest bandwidth, the ring width $(a)$ and ring height $(b)$ of 7.20 and $3.40 \mathrm{~cm}$ are chosen for experiment.
TABLE 1: The optimal parametric values of the proposed antenna.

\begin{tabular}{lcc}
\hline Parameters & Physical size & Electrical size $(\lambda)$ \\
\hline$L$ & $16.0 \mathrm{~cm}$ & 1.2307 \\
$a$ & $7.2 \mathrm{~cm}$ & 0.5538 \\
$b$ & $3.4 \mathrm{~cm}$ & 0.2615 \\
$d$ & $2.6 \mathrm{~cm}$ & 0.2000 \\
$h$ & $2.4 \mathrm{~cm}$ & 0.1846 \\
$r_{c}$ & $1.1 \mathrm{~cm}$ & 0.0846 \\
$t$ & $2.0 \mathrm{~mm}$ & \\
$\delta$ & & $1.0 \mathrm{~mm}$ \\
\hline
\end{tabular}

The inclusion of the CDM into the rectangular ring antenna is to increase the antenna's frequency bandwidth to cover the WiMAX band of $2.300-5.825 \mathrm{GHz}$. Figure 6 illustrates the frequency response curves as a function of $\left|S_{11}\right|$ and the frequency for the CDM radii of 1.00 to $1.40 \mathrm{~cm}$ and constant feed gap $(\delta)$ of $1.00 \mathrm{~mm}$. Even though the $\left|S_{11}\right|$ curves for five CDM radii follow a similar pattern, an $r_{c}$ of $1.10 \mathrm{~cm}$ is selected as it gives the highest overall efficiency in terms of impedance bandwidth, radiation pattern, and gain.

In addition, the effect of the feeding gap $(\delta)$ is examined and the results are depicted in Figure 7. It is found that varying the feeding gap $(\delta)$ impacts the impedance bandwidth. That is, a reduction in $\delta$ from $1.50 \mathrm{~mm}$ to $0.50 \mathrm{~mm}$ causes the impedance bandwidth to become narrower and thereby fails to cover the entire WiMAX frequency band. Based on Figure 7, the feeding gap $(\delta)$ of $1.00 \mathrm{~mm}$ is chosen for the widest impedance bandwidth which covers the entire WiMAX band. Table 1 presents the optimal parametric values from the simulation of the proposed antenna.

\section{Measured Results}

To validate the simulation results, a prototype antenna was fabricated based on the optimal parameters in Table 1. Figure 8 is a photograph image of the prototype antenna.

4.1. Impedance Bandwidth. The measurements of impedance bandwidth, radiation pattern, and gain were taken using an HP8720C Network Analyzer. A comparison of the simulated and measured $\left|S_{11}\right|$, represented, respectively, by a solid line and a dashed line, is presented in Figure 9. The simulated impedance bandwidth $\left(\left|S_{11}\right|<-10 \mathrm{~dB}\right)$ of $88 \%$ was achieved in a frequency range of $2.28-5.91 \mathrm{GHz}$ (central frequency of $4.095 \mathrm{GHz}$ ), while that of the prototype antenna of $93 \%$ was in a frequency of $2.16-5.96 \mathrm{GHz}$ (central frequency of $4.06 \mathrm{GHz}$ ). It is found that the simulation and measured results are in reasonable agreement. In addition, the frequency ranges of both simulation and experiment satisfy the WiMAX requirement.

Figure 10 illustrates a comparison of the gain along the $2.300-5.825 \mathrm{GHz}$ frequency range of the prototype antenna and that of the simulation, in which the former is represented by a solid line and the latter by a dashed line. The minimum 


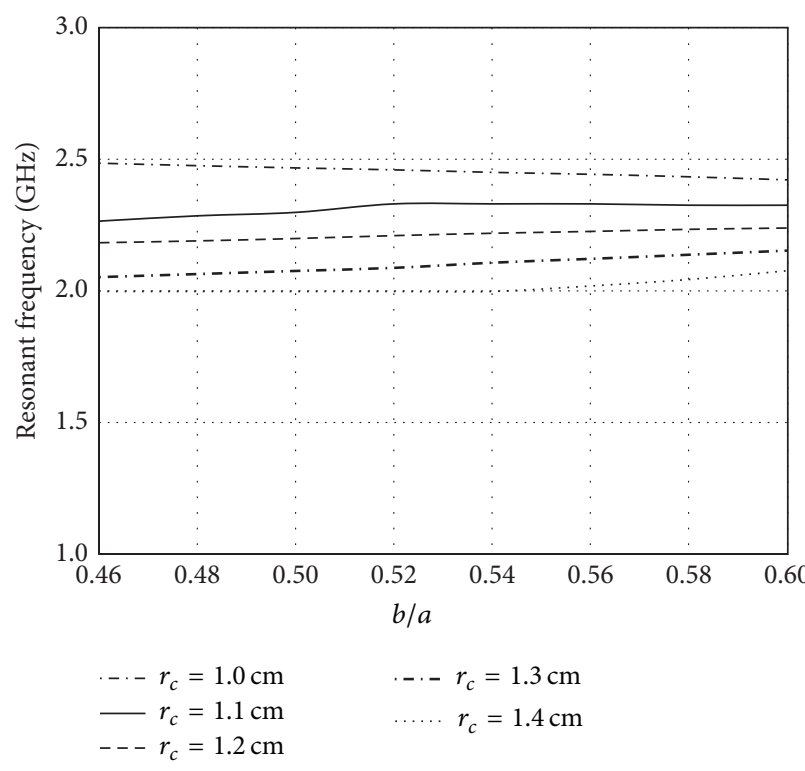

(a) The minimum frequency of resonance at $2.3 \mathrm{GHz}$ by varying $r_{c}$

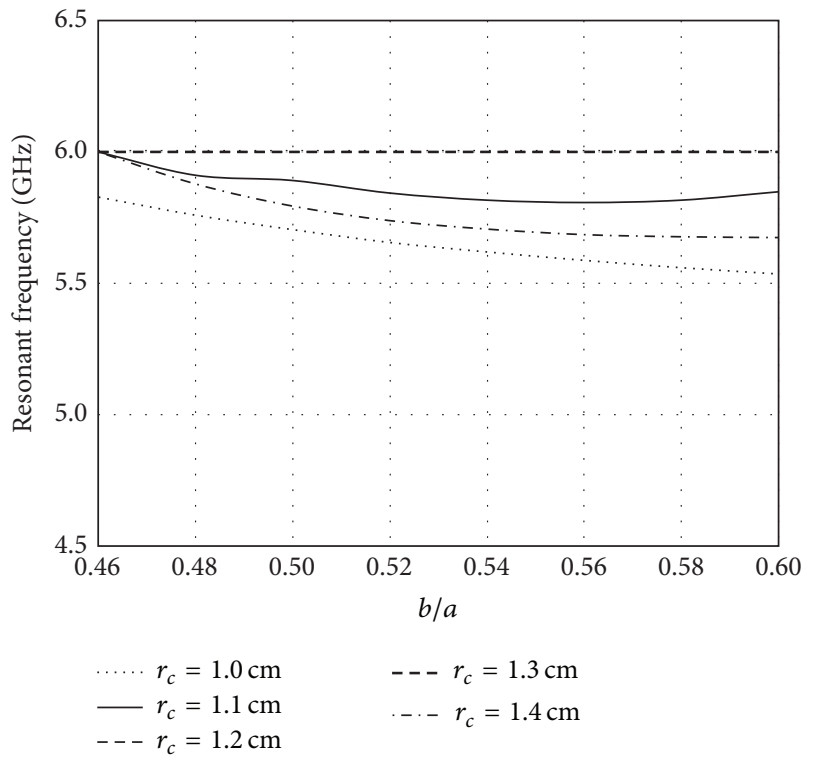

(b) The maximum frequency of resonance at $2.3 \mathrm{GHz}$ by varying $r_{c}$

FIGURE 4: The resonant frequency relative to $b / a$ for various $r_{c}(a=7.20 \mathrm{~cm}, d=2.60 \mathrm{~cm}$, and $h=2.40 \mathrm{~cm})$.

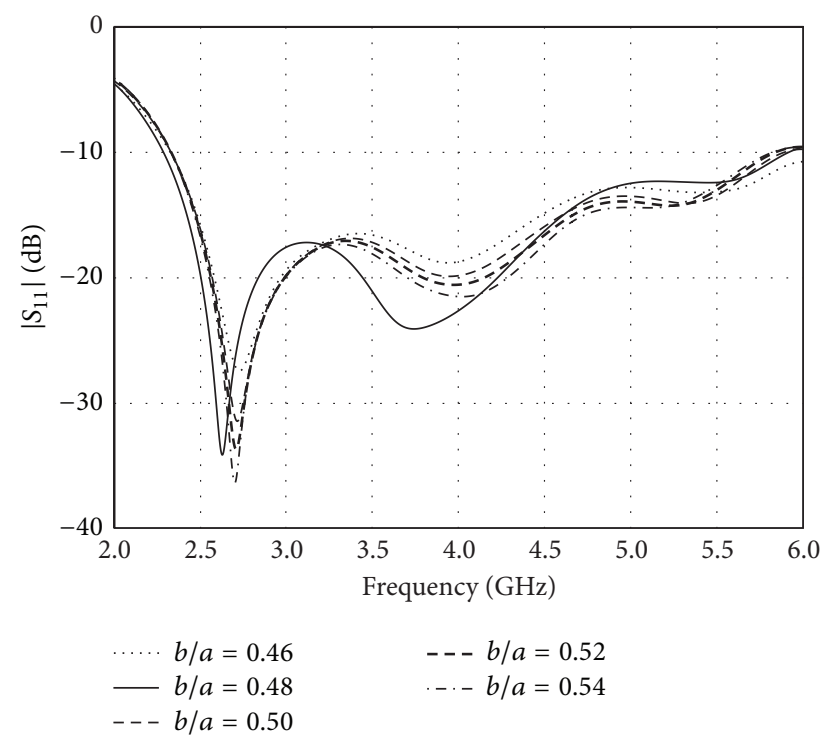

FIGURE 5: $\left|S_{11}\right|$ versus frequency as a function of $b / a(a=$ $7.20 \mathrm{~cm}, d=2.60 \mathrm{~cm}, h=2.40 \mathrm{~cm}$, and $r_{c}=1.10 \mathrm{~cm}$ ).

and maximum gains are 3.4 and $9.3 \mathrm{dBi}$ for the simulation and 3.7 and $8.7 \mathrm{dBi}$ for the prototype antenna.

4.2. Radiation Pattern. Figures 11 and 12 illustrate the simulation and measured radiation patterns in the $y z$ - and $x z$ planes, respectively, at $2.5,3.5$, and $5.5 \mathrm{GHz}$. In Figure 11, the beam peaks direct in the $3+z$ direction. The radiation pattern

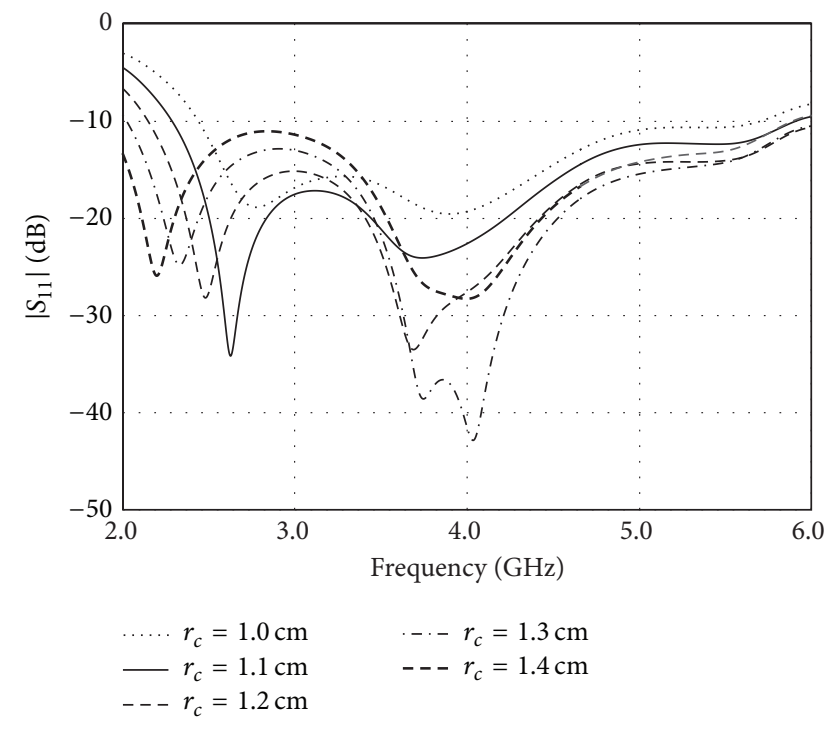

FIGURE 6: $\left|S_{11}\right|$ relative to frequency as a function of $r_{c}(\delta=$ $1.00 \mathrm{~mm})$.

in the $y z$-plane at $5.5 \mathrm{GHz}$ slightly tilts upward from the $z$ axis as a result of the CDM installation on the rectangular ring base. The CDM contributes to the asymmetrical areas between the upper and lower portions of the ring chamber. However, the radiation pattern in the $x z$-plane is symmetrical because of the symmetrical areas between the left and right portions of the ring chamber. The simulation and measured radiation patterns show good agreement. At $2.5 \mathrm{GHz}$, the 


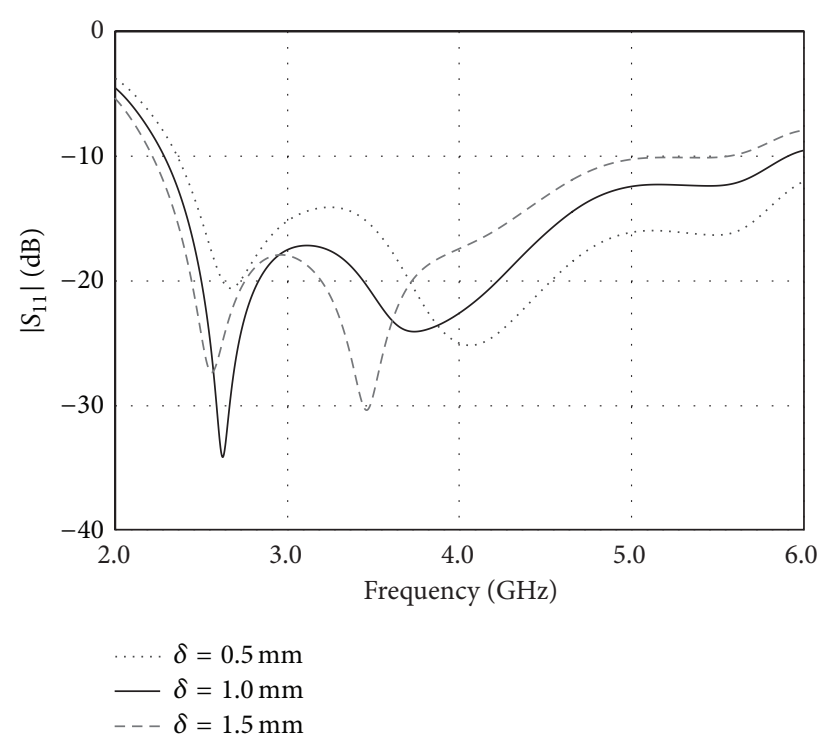

Figure 7: $\left|S_{11}\right|$ relative to frequency as a function of $\delta$.

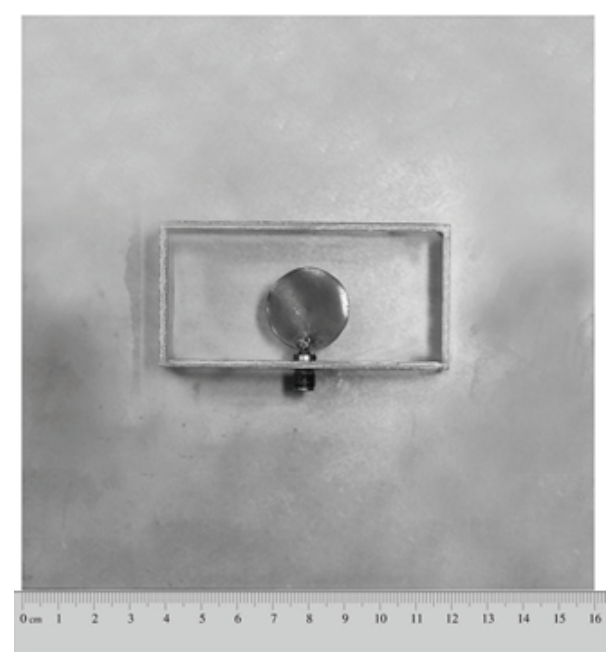

FIGURE 8: Photograph image of the prototype antenna.

measured half-power beamwidth (HPBW) in the $y z$-and $x z$-planes is 73 and 62 degrees. At $3.5 \mathrm{GHz}$, the measured HPBWs in the $y z$-and $x z$-planes are identical at 80 degrees, while those at $5.5 \mathrm{GHz}$ are 28 and 40 degrees, respectively. The measured front-to-back ratio $(F / B)$ in both $y z$ - and $x z$ planes is greater than $20 \mathrm{~dB}$. Thus, the proposed antenna produces a good radiation pattern and is a very good unidirectional antenna.

\section{Conclusions}

The unidirectional antenna suitable for WiMAX is developed using the CDM-excited rectangular ring mounted in front

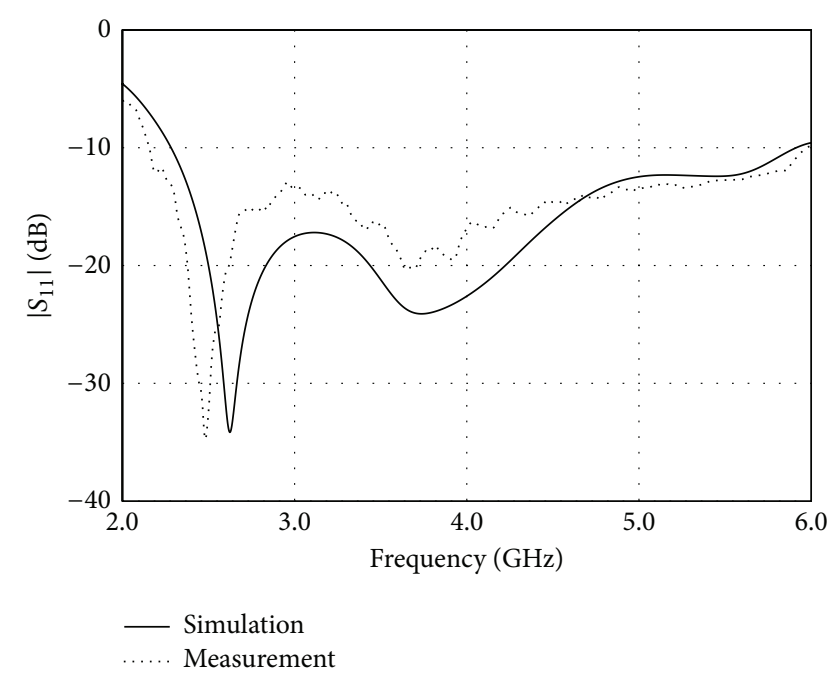

FIGURE 9: The comparison of the simulation and measured $\left|S_{11}\right|$ relative to frequency.

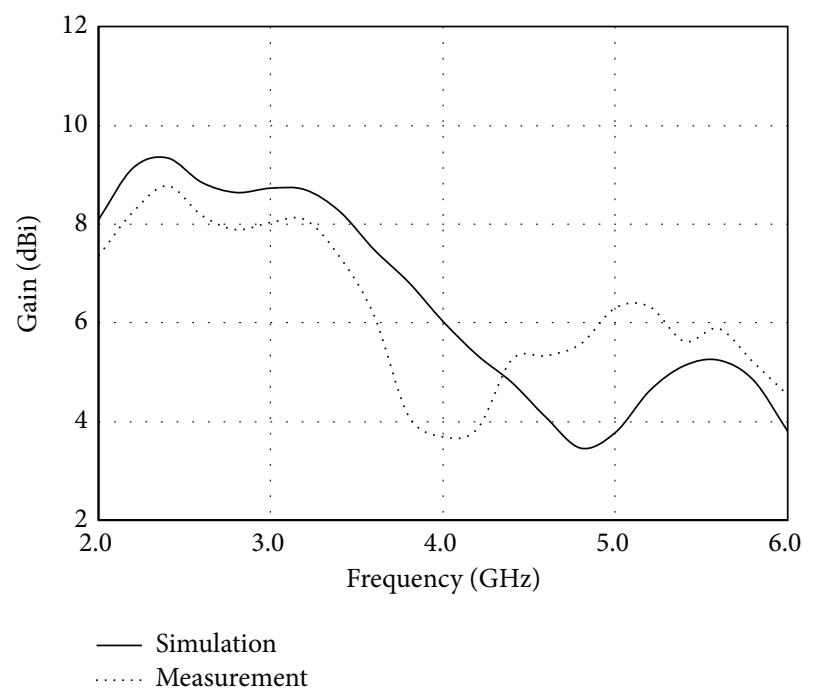

FIGURE 10: The simulated and measured gains relative to frequency.

of the square reflector. The design principle is simple and straightforward. In addition, the antenna can be fabricated and manufactured on a large scale. At $2.5 \mathrm{GHz}$, the measured HPBWs in the $y z$ - and $x z$-planes are 72 and 62 degrees, respectively. At $3.5 \mathrm{GHz}$, the measured HPBWs in both planes are identical at 80 degrees, while those at $5.5 \mathrm{GHz}$ are 28 and 40 degrees, respectively. The measured $F / B$ in both $y z$ - and $x z$-planes are greater than $20 \mathrm{~dB}$. The antenna has a good radiation pattern suitable for the pointto-point communications and can achieve the impedance bandwidth $\left(\left|S_{11}\right|<-10 \mathrm{~dB}\right)$ of $93 \%$, covering the frequency range of 2.16-5.96 GHz. Its compact size and good radiation performance render the proposed antenna suitable for the WiMAX applications. 


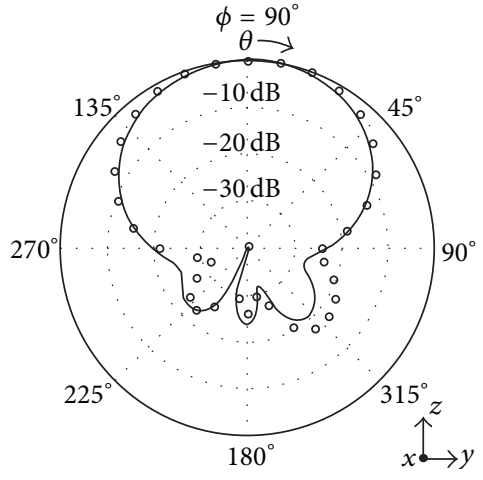

- Simulation

○00000 Measurement

(a) $2.5 \mathrm{GHz}$

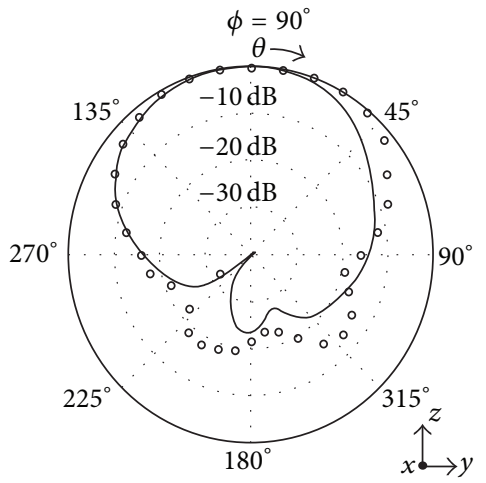

- Simulation

(b) $3.5 \mathrm{GHz}$

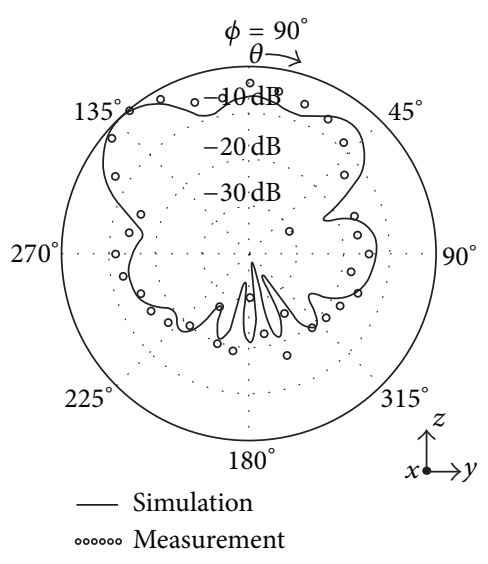

(c) $5.5 \mathrm{GHz}$

FIGURE 11: The comparison between the simulated and measured radiation patterns in the $y z$-plane.

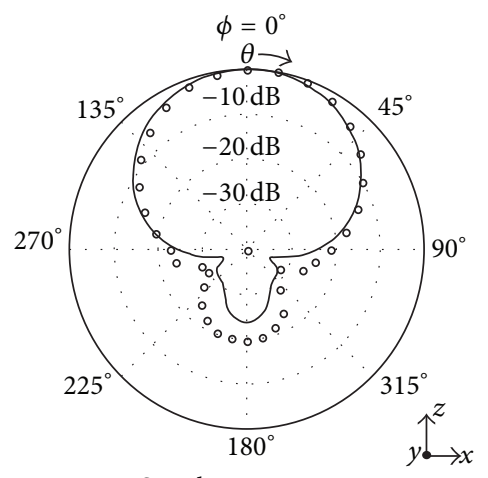

- Simulation

oooooo Measurement

(a) $2.5 \mathrm{GHz}$

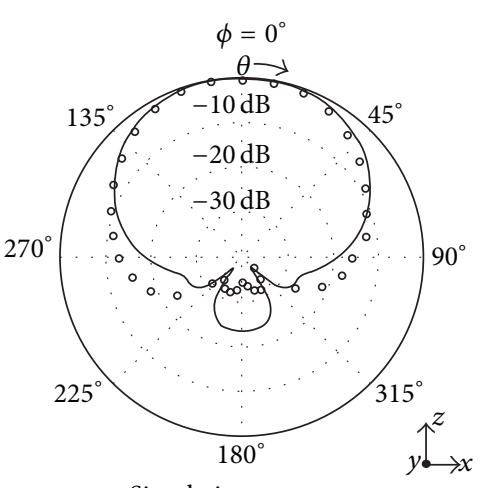

- Simulation

oooooo Measurement

(b) $3.5 \mathrm{GHz}$

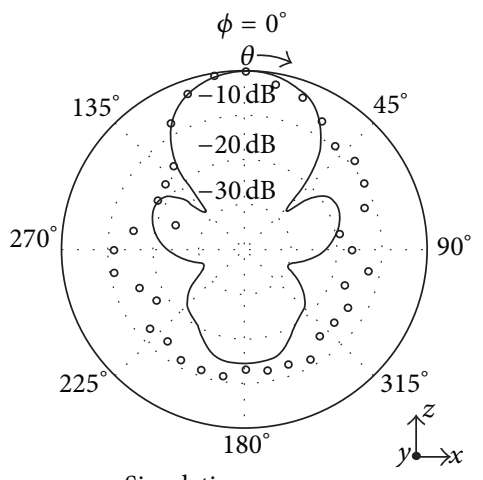

- Simulation

0.0000 Measurement

(c) $5.5 \mathrm{GHz}$

FIGURE 12: The comparison between the simulated and measured radiation patterns in the $x z$-plane.

\section{Conflict of Interests}

This paper is part of the lead author's Ph.D. degree dissertation. The authors ascertain that the use of CST Microwave Studio in this research paper presents no conflict of interests.

\section{Acknowledgments}

This research work is fully sponsored by the AUN/SeedNet Program. The comments from anonymous reviewers to improve this paper are greatly appreciated.

\section{References}

[1] IEEE Std 802.16a-2003, "IEEE Standard for Local and Metropolitan Area Networks-Part 16: Air Interface for Fixed Broadband Wireless Access Systems-Amendment 2: Medium Access Control Modifications and Additional Physical Layer Specifications for 2-11 GHz," 2003.

[2] IEEE, "IEEE standard for local and metropolitan area networks part 16: air interface for fixed broadband wireless access systems," IEEE Std 802.16-2004, 2004, (Revision of IEEE Std 802.16-2001).

[3] F. Ohrtman, WiMAX Handbook Building 802.16 Wireless Networks, McGraw-Hill Communications, 2005.

[4] C.-Y. Pan, T.-S. Horng, W.-S. Chen, and C.-H. Huang, "Dual wideband printed monopole antenna for WLAN/WiMAX applications," IEEE Antennas and Wireless Propagation Letters, vol. 6, pp. 149-151, 2007.

[5] J. Wu, Z. Zhao, Z. Nie, and Q. H. Liu, "A broadband unidirectional antenna based on closely spaced loading method," IEEE Transactions on Antennas and Propagation, vol. 61, no. 1, pp. 109-116, 2013.

[6] S. Kosulvit, M. Krairiksh, C. Phongcharoenpanich, and T. Wakabayashi, "A simple and cost-effective bidirectional antenna using a probe excited circular ring," IEICE Transactions on Electronics, vol. E84-C, no. 4, pp. 443-450, 2001.

[7] F. Elek, R. Abhari, and G. V. Eleftheriades, "A uni-directional ring-slot antenna achieved by using an electromagnetic bandgap surface," IEEE Transactions on Antennas and Propagation, vol. 53, no. 1, pp. 181-190, 2005.

[8] K. Agarwal, Nasimuddin, and A. Alphones, "Unidirectional wideband circularly polarised aperture antennas backed 
with artificial magnetic conductor reflectors," IET Journal Microwave, Antennas \& Propagation, vol. 7, no. 5, pp. 338-346, 2013.

[9] Z. Y. Zhang, G. Fu, S. L. Zuo, and S. X. Gong, "Wideband unidirectional patch antenna with $\Gamma$-shaped strip feed," Electronics Letters, vol. 46, no. 1, pp. 24-26, 2010.

[10] G. M. Zhang, J. S. Hong, B. Z. Wang, G. Song, and P. Zhang, "Compact wideband unidirectional antenna with a reflector connected to the ground using a stub," IEEE Antennas and Wireless Propagation Letters, vol. 10, pp. 1186-1189, 2011.

[11] Y. Zhao, K. Wei, Z. Zhang, and Z. Feng, "A waveguide antenna with bidirectional circular polarizations of the same sense," IEEE Antennas and Wireless Propagation Letters, vol. 12, pp. 559-562, 2013.

[12] W. Li, J. Qiu, and Y. Suo, "Design and simulation of novel ultra wideband planar reflector antenna," in Proceedings of the International Conference on Microwave and Millimeter Wave Technology (ICMMT '07), pp. 1-4, April 2007.

[13] C. Phongcharoenpanich, S. Lamultree, S. Kosulvit, and M. Krairiksh, "A unidirectional beam antenna using a probe excited rectangular ring near the reflector," in Proceedings of the $3 \mathrm{rd}$ International Conference on Microwave and Millimeter Wave Technology (ICMMT '02), pp. 389-392, August 2002.

[14] C. Phongcharoenpanich, S. Lamultree, S. Kosulvit, M. Krairiksh, and J. Takada, "Analysis of a dihedral corner reflector antenna excited by a probe inside rectangular ring," in Proceedings of the International Symposium on Antennas and Propagation, pp. 225-228, 2004.

[15] J. D. Kraus, “The corner-reflector antenna," The Proceedings of the IRE, vol. 28, pp. 513-519, 1940.

[16] P. Lam, S.-W. Lee, K. Lang, and D. Chang, "Sidelobe reduction of a parabolic reflector with auxiliary reflectors," IEEE Transactions on Antennas and Propagation, vol. 35, no. 12, pp. 1367-1374, 1987.

[17] G. Ketwan, C. Phongcharoenpanich, and S. Kosulvit, "A wideband unidirectional antenna using conical reflector fed by circular ring," in Proceedings of the Asia-Pacific Microwave Conference (APMC '05), vol. 5, pp. 2939-2942, 2005.

[18] M. J. Ammann and Z. N. Chen, "Wideband monopole antennas for multi-band wireless systems," IEEE Antennas and Propagation Magazine, vol. 45, no. 2, pp. 146-150, 2003.

[19] J. Liang, L. Guo, C. C. Chiau, X. Chen, and C. G. Parini, "Study of CPW-fed circular disc monopole antenna for ultra wideband applications," IEE Proceedings-Microwave and Antennas Propagation, vol. 152, pp. 505-508, 2005.

[20] N. P. Agrawall, G. Kumar, and K. P. Ray, "Wide-band planar monopole antennas," IEEE Transactions on Antennas and Propagation, vol. 46, no. 2, pp. 294-295, 1998.

[21] Z. N. Chen, M. J. Ammann, M. Y. W. Chia, and T. S. P. See, "Annular planar monopole antennas," IEE Proceedings: Microwaves, Antennas and Propagation, vol. 149, no. 4, pp. 200203, 2002.

[22] M. Hammoud, P. Poey, and F. Colombel, "Matching the input impedance of a broadband disc monopole," Electronics Letters, vol. 29, no. 4, pp. 406-407, 1993.

[23] CST-Microwave Studio, User's Manual, 2006. 

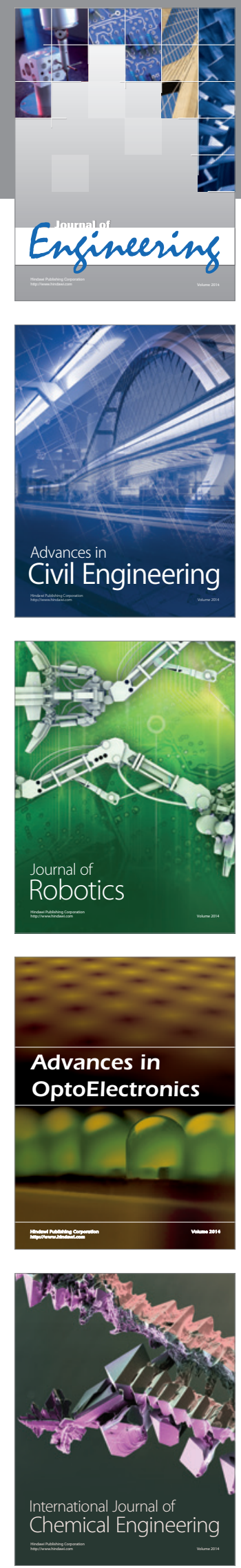

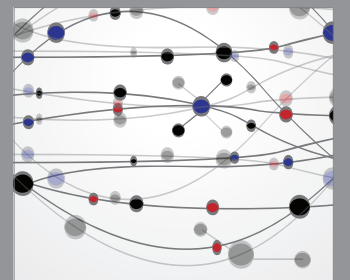

The Scientific World Journal
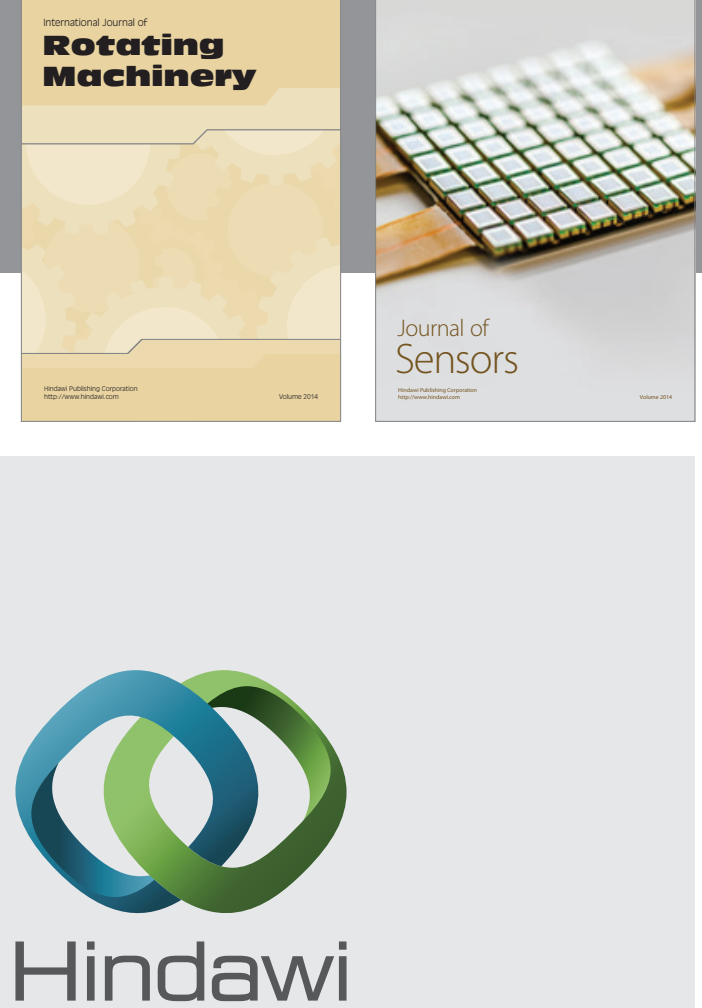

Submit your manuscripts at http://www.hindawi.com
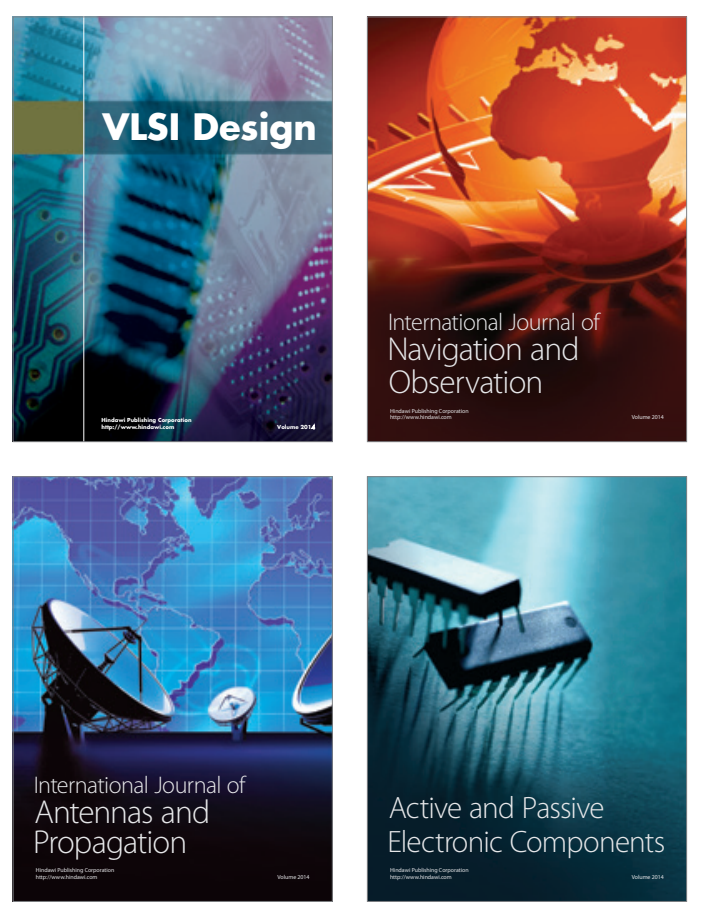
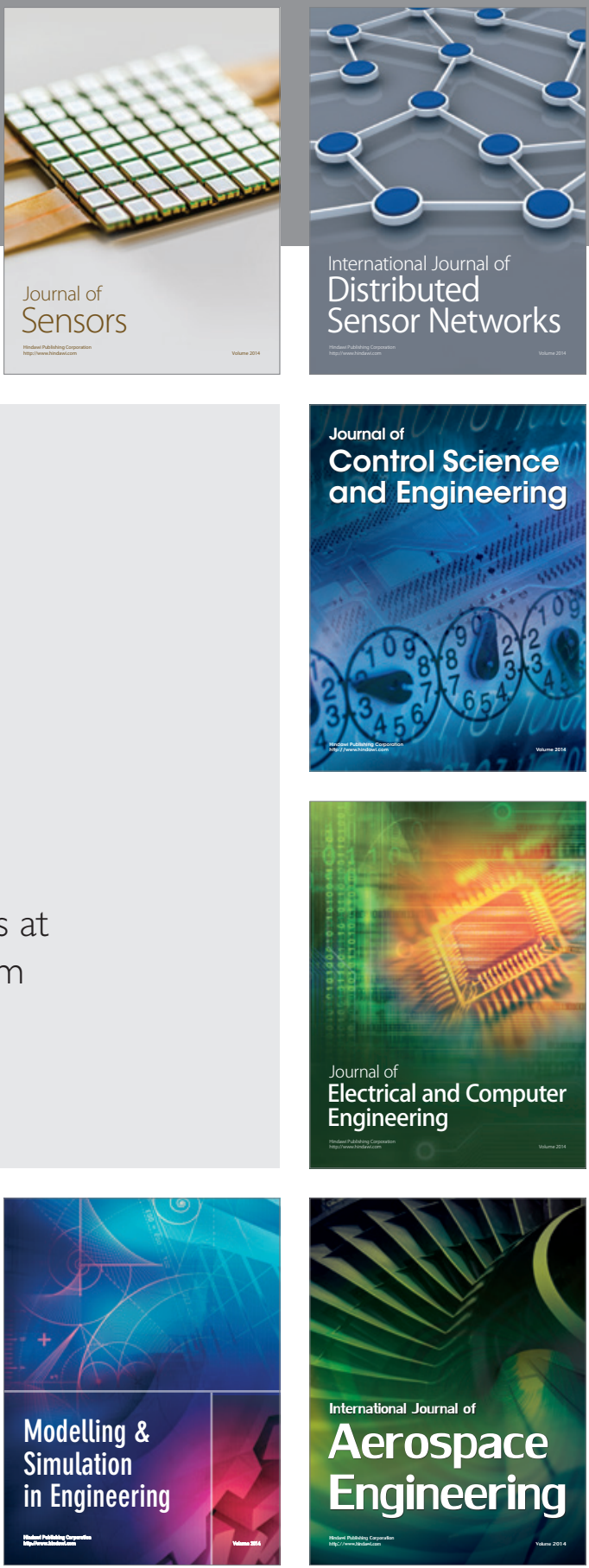

Journal of

Control Science

and Engineering
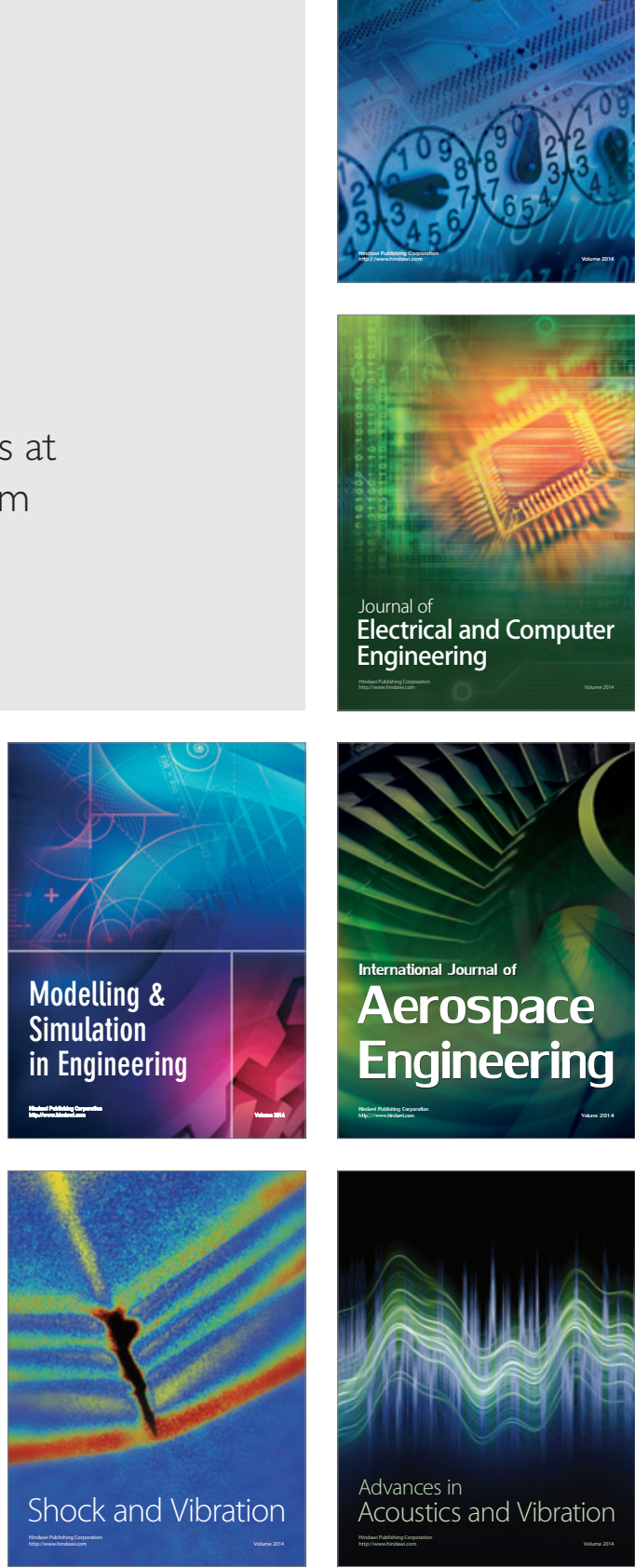